\title{
Comparative Analysis of Salinity-Induced Proteomic Changes in Cotton (Gossypium hirsutum L.)
}

\author{
Yupeng Cui*, Xuke Lu*, Delong Wang, Junjuan Wang, Zujun Yin, Weili Fan, Shuai Wang, \\ Wuwei Ye" \\ State Key Laboratory of Cotton Biology, Institute of Cotton Research of Chinese Academy of Agricultural \\ Sciences, Anyang, China \\ Email: \#yew158@163.com
}

Received 14 November 2014; accepted 1 December 2014; published 16 January 2015

Copyright (C) 2015 by authors and Scientific Research Publishing Inc.

This work is licensed under the Creative Commons Attribution International License (CC BY). http://creativecommons.org/licenses/by/4.0/

(c) (i) Open Access

\section{Abstract}

Salt stress on cotton varieties of distinct salinity tolerance can induce expression of different proteins. Zhong 07, a salt-tolerant variety and Zhong s9612, a salt-sensitive variety, were utilized as experimental materials. The leaves of trefoil seedlings treated with or without $0.4 \% \mathrm{NaCl}$ for $24 \mathrm{~h}$ were harvested for whole-protein extraction. Two-dimensional technology, combined with mass spectroscopy (MS) analysis and protein database searching, was employed to detect differentially expressed proteins and determine their identities and biological functions. Compared with the control, Zhong 07 showed 10 differentially expressed proteins under salt stress, of which 6 were upregulated and 4 were downregulated. Meanwhile, 12 differentially expressed proteins were detected in Zhong s9612 under salt stress, of which 10 were upregulated and 2 were downregulated. In the matrix-assisted laser desorption-ionization/time of flight-time of flight/MS analysis, 14 differentially expressed proteins were successfully identified, including the ribulose-1, 5-bisphosphate carboxylase/oxygenase (RuBisco) large subunit-binding protein subunit alpha (RuBisco $\alpha$ ), luminal binding protein (LBP), heat shock protein 70 (Hsp1, 2, 3), pathogenesis-related protein class 10 (PR-10), quinoneoxidoreductase-like protein (QOR), S-adenosylmethioninesyn-thetase (SAMS), enolase (EN), and RuBisco large subunit-binding protein subunit beta (RuBisco $\beta$ ). Cellular function is ultimately executed by proteins, and cotton varieties with different salt tolerance can be influenced by salt stress to various degrees, which can provide certain theoretical foundation for the identification of salt tolerance of cotton varieties. The findings also provide some proteins, such as the RuBisco large subunit binding proteins $\alpha$ and $\beta$ subunits, OEE2 protein, HSP70, and S-adenosylmethioninesynthetase, which can be used as protein markers of salt-to-lerance before- and post-treatment, making a big difference in salt-tolerance identification in cotton.

\footnotetext{
*These authors contributed equally to this work.

${ }^{\#}$ Corresponding author.
}

How to cite this paper: Cui, Y.P., Lu, X.K., Wang, D.L., Wang, J.J., Yin, Z.J., Fan, W.L., Wang, S. and Ye, W.W. (2015) Comparative Analysis of Salinity-Induced Proteomic Changes in Cotton (Gossypium hirsutum L.). Agricultural Sciences, 6, 78-86. 


\section{Keywords}

\section{Upland Cotton (Gossypium hirsutum L.), Salt Stress, Differential Protein, Mass Spectrum Analysis}

\section{Introduction}

Soil salinization is widely distributed among the northwest, northeast, and coastal regions of China. Salt stress can strongly affect crop yield, protein synthesis, photosynthesis, and energy metabolism [1]. An increase in the salt concentration in soil can significantly impede the normal growth of cotton (Gossypium hirsutum L.) seedlings and thus result in physiological yield loss and death [2] [3]. Therefore, salt stress in soil has become one of the key abiotic factors threatening cotton seedling development and production. Cotton is one of the species with strong salt tolerance and is a pioneering crop in saline land. Previous studies have discussed the effects of salt on photosynthesis [4]-[7], antioxidants [8] [9], seed germination [10] [11], and cellular structure [12]. Moreover, cotton has been found to perceive and respond to various adversities, including salt stress.

Differential proteomics has emerged as a new field in the post-genomic era. This method can effectively reflect plant physiological states under different conditions and the corresponding regulation mechanism. The differentially expressed protein spots detected by differential proteomics are normally the key regulation proteins [13]. However, to date, only a few reports on the effect of salt stress on the cotton leaf proteome have been published. Thus, in the current study, the salt-tolerant and salt-sensitive cotton varieties Zhong 07 and Zhong s9612, respectively, were utilized to investigate the differentially expressed proteins under salt stress through a proteomic approach. The current study aims to discover proteins related to salt tolerance, deepen the understanding of salt tolerance in cotton, and provide theoretical guidelines and relevant markers for the identification of cotton salt tolerance and selection of salt-tolerant varieties.

\section{Materials and Methods}

\subsection{Plant Materials and Stress Application}

The salt-tolerant and salt-sensitive varieties Zhong 07 and Zhong s9612, respectively, were chosen as experimental materials. The cotton seedlings were grown in a greenhouse at the Chinese Academy of Agricultural Sciences, Cotton Research Institute, and the sand culture method was used. When reaching the trefoil stage, the samples were treated with $0.4 \% \mathrm{NaCl}$ (of the sand used to grow cotton seedlings in the plant pots) [14]. The seedlings before salt stress were used as the control $(0 \mathrm{~h})$. The true leaves from control and stressed seedlings after $24 \mathrm{~h}$ of treatment were collected, flash frozen in liquid nitrogen, and stored in $-80^{\circ} \mathrm{C}$ until use. The samples were assayed thrice.

\subsection{Leaf Protein Extraction}

The leaf proteins were extracted according to the trichloroacetic acid (TCA)-acetone method [15] [16] with minor modifications. The mortar was precooled with liquid nitrogen, and 0.3 gpolyvinylpyrrolidone was added to $0.5 \mathrm{~g}$ to $1 \mathrm{~g}$ of leaves. The samples were ground into fine powder, transferred into a $50 \mathrm{~mL}$ microtube, and resuspended in $3 \mathrm{vol}$ of TCA-acetone solution (containing 10\% TCA and $0.07 \% \beta$-mercaptoethanol) precooled at $-20^{\circ} \mathrm{C}$. Then, they were thoroughly vortexed and incubated at $-20^{\circ} \mathrm{C}$ overnight for protein precipitation. After centrifugation $\left(4^{\circ} \mathrm{C}, 1 \mathrm{~h}, 15,000 \mathrm{~g}\right)$, the upper supernatant was discarded, and the remaining pellets were collected. Then, 3 vol of acetone solution (containing $0.07 \% \beta$-mercaptoethanol) prechilled at $-20^{\circ} \mathrm{C}$ was added, and the samples were vortexed and incubated at $-20^{\circ} \mathrm{C}$ for $2 \mathrm{~h}$. Thereafter, the samples were centrifuged as aforementioned, and the supernatant was discarded. This step was repeated three times. Finally, the remaining pellets were air dried and stored at $-80^{\circ} \mathrm{C}$ until use.

One milligram of dry powder was resuspended in $30 \mu \mathrm{L}$ of lysis buffer (7 M urea, 4\% CHAPS, $40 \mathrm{mM}$ DTT, and $2 \mathrm{M}$ thiourea), incubated on ice without disturbance until the pellets were fully soaked, and then vortexed every $10 \mathrm{~min}$ to $20 \mathrm{~min}$ until the pellets were completely dissolved. After centrifugation $\left(4^{\circ} \mathrm{C}, 1 \mathrm{~h}, 100,000 \mathrm{~g}\right)$, the supernatant was divided into aliquots and stored at $-80^{\circ} \mathrm{C}$ until use. 


\subsection{Protein Quantification}

The protein concentration was determined using a two-dimensional (2D)-quant kit according to the manufacturer's instructions (GE Healthcare, number 061101). Bovine serum albumin $(2 \mathrm{mg} / \mathrm{mL}$ ) was used to construct the standard curve. A Beckman DU800 spectrophotometer was used to quantify the absorbance of both sample protein and standard solution at $480 \mathrm{~nm}$.

\subsection{Reagents and Chemicals}

The immobilized $\mathrm{pH}$ gradient (IPG) strip (pH 4 to 7, $24 \mathrm{~cm}$, linear gradient) and cover fluid were purchased from GE healthcare life sciences (Beijing, China). The acrylamide, bromophenol blue, Tris-base, 3-[(3-cholamidopropyl)dimethylammonio]-1-propanesulfonate (CHAPS), iodoacetamide, ammonium persulfate, sodium dodecyl sulfate (SDS), bisacrylamide, glycine, Coomassie brilliant blue (CBB) G-250, urea, glutaraldehyde, and dithiothreitol (DTT) were all purchased from Amresco. The agarose and glycerol were purchased from Solarbio. All other chemicals were from China and were of analytical grade.

\subsection{D Electrophoresis}

Rehydration buffer (8 M urea, 2\% CHAPS, 0.3\% DTT, and 0.6\% IPG buffer) was used to resuspend $0.1 \mathrm{mg}$ of protein pellets. The loading volume was maintained at $450 \mu \mathrm{L}$. IPG strips (pH 4 to 7, $24 \mathrm{~cm}$, linear gradient) were selected for isoelectric focusing (IEF). IEF was performed in an EttanIPGPhor (GE Biosciences) at $18^{\circ} \mathrm{C}$ according to the following program: $30 \mathrm{~V}$ for $8 \mathrm{~h}, 50 \mathrm{~V}$ for $4 \mathrm{~h}, 100 \mathrm{~V}$ for $1 \mathrm{~h}, 300 \mathrm{~V}$ for $1 \mathrm{~h}, 500 \mathrm{~V}$ for $1 \mathrm{~h}, 1000$ $\mathrm{V}$ for $1 \mathrm{~h}, 8000 \mathrm{~V}$ for $12 \mathrm{~h}$, and $500 \mathrm{~V}$ until completion. After IEF, the IPG strips were equilibrated in two equilibration buffers for $15 \mathrm{~min}$ each. The first one contained $1.5 \mathrm{M}$ Tris- $\mathrm{HCl}$ (pH 8.8), $6 \mathrm{M}$ urea, 30\% glycerol, $2 \%$ SDS, and 1\% DTT. The second one contained $1.5 \mathrm{M}$ Tris- $\mathrm{HCl}$ (pH 8.8), $6 \mathrm{M}$ urea, 30\% glycerol, 2\% SDS, and $4 \%$ iodoacetamide. After equilibration, 2D (12.5\%) SDS-PAGE was performed on an ETTAN DALT SIT ELECT UNIT230 System. The procedure was as follows: $2 \mathrm{~W}$ for $45 \mathrm{~min}$ and $15 \mathrm{~W}$ for $5 \mathrm{~h}$ for every strip at a constant temperature of $16^{\circ} \mathrm{C}$. The gels were visualized via silver and CBB staining.

\subsection{Gel Image Acquisition and Matrix-Assisted Laser Desorption-Ionization/Time of Flight/Time of Flight (MALDI/TOF-TOF)/Mass Spectroscopy (MS) Analysis}

After silver staining, the gels were scanned using an image scanner. The image analysis was performed using the Image Master 2D Platinum Software Version 5.0 (GE Healthcare) following the user's manual. The protein spots were quantified using the percentage of spot volume (vol\%) criterion. The salt-stressed (reference gel, $24 \mathrm{~h}$ ) and control (analytical gel, $0 \mathrm{~h}$ ) groups were comparatively studied. Differentially expressed protein spots were then determined. All different selected spots were manually excised from the 2-DE gels, and in-gel digestion. The experiment was performed in triplicate to guarantee reliable results. And then the spots selected were subject to MALDI-TOF-MS ananlysis. MALDI-TOF-MS ananlysis can deliver high resolution and accurate mass determination of biomolecules including protein digests, which is completed by biotech company (CapitalBio Corporation in China).

\section{Results}

\subsection{Proteomic Profiling of Cotton Leaves at the Trefoil Stage under Salt Stress}

An IPG strip (pH 4 to 7, 24 cm, linear gradient; GE) and the IEF/SDS-PAGE technique were utilized to profile the proteomic changes in the salt-tolerant and salt-sensitive varieties Zhong 07 and Zhong s9612, respectively, in response to $24 \mathrm{~h}$ salt stress. After silver staining, 2-DE gel maps with high resolution and reproducibility were obtained (Figure 1). After the ImageMaster-2D Elite 5.0 analysis of the salt-stressed and control groups, on average, 624 reproducible protein spots for Zhong 07 and 818 protein spots for Zhong s9612 were captured. The salt-stressed and control groups of Zhong 07 and Zhong s9612 were then comparatively studied. The results showed that the number and type of proteins were roughly the same between the treatment and control groups, with only a fraction of proteins showing significant changes. Further analysis using ImageMaster-2D Elite 5.0 revealed that, compared with the control, Zhong 07 had 10 protein spots that showed significant changes after salt stress, of which 6 were unregulated and 4 were down regulated. For Zhong s9612, 12 differentially ex- 
pressed proteins were detected under salt stress, of which 10 were unregulated and 2 were down regulated. These results can be clearly obtained from the enlarged picture of the expression pattern of the same spot between the control and stressed groups (Figure 2).

A big difference exits in the proteins of different cotton varieties with distinct salt-tolerance under the $\mathrm{NaCl}$ salinity. The reasons for which, on the one hand, is determined by the genotype of the cotton varieties, on the other hand may be different response to the salt stress. From the Figure 2, we can identified 9 protein spots which were significantly unregulated $(1,2,3,7,9,15,16,20,22)$, and 2 were significantly down regulated (6, 13). So we can speculate that the protein spots of big difference between salt-tolerant materials and salt-sensitive materials could be used as a method of screening Salt-tolerant germplasm.
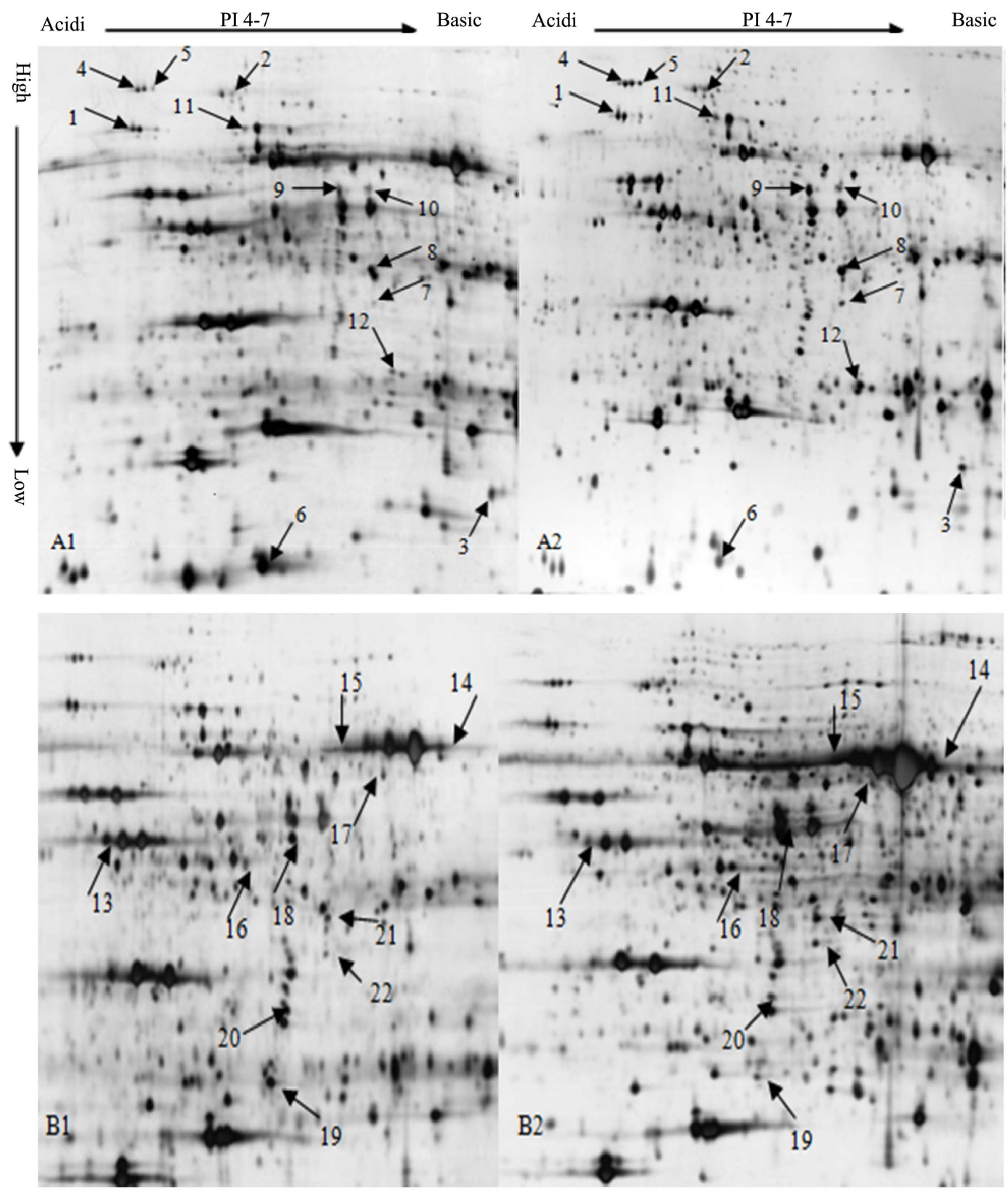

Figure 1. The proteome profiles of leaves of cotton at trefoil stage in response to salt stress. (A1) The control group of Zhong s9612; (A2) The salt-stressed group of Zhong s9612; (B1) The control group of Zhong 07; (B2) The salt-stressed group of Zhong $07.0 .4 \% \mathrm{NaCl}$ (of the sand used to grow cotton seedlings in the plant plots) was added and leaves were harvested from control and stressed seedlings at 24 post-treatment. Data are representative of 3 replicates. 
A

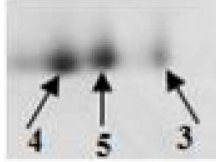

B

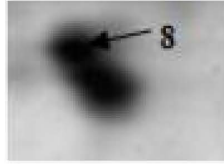

\section{1}
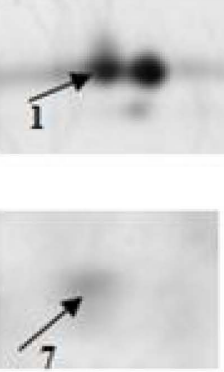
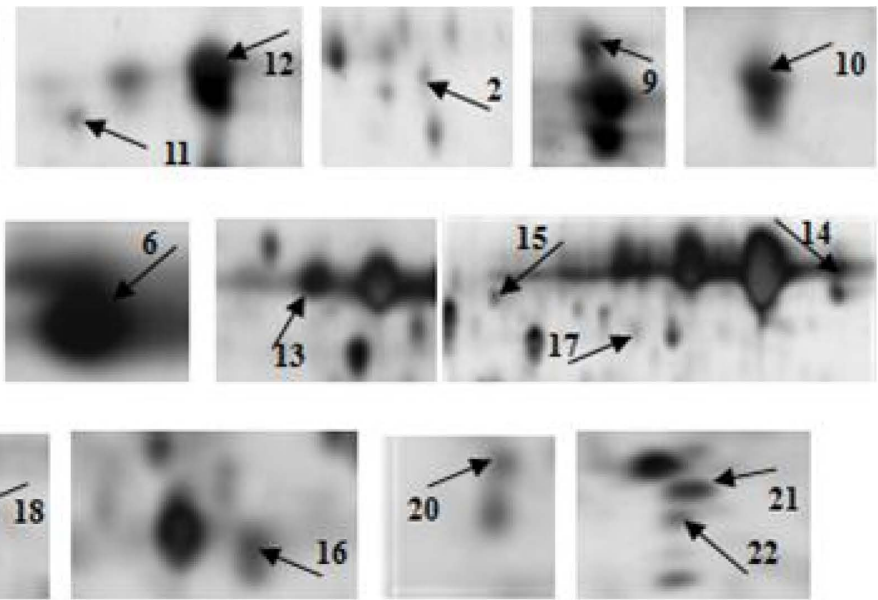

18

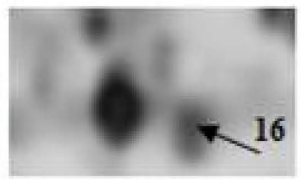

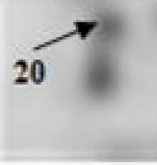

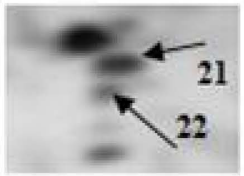

A1
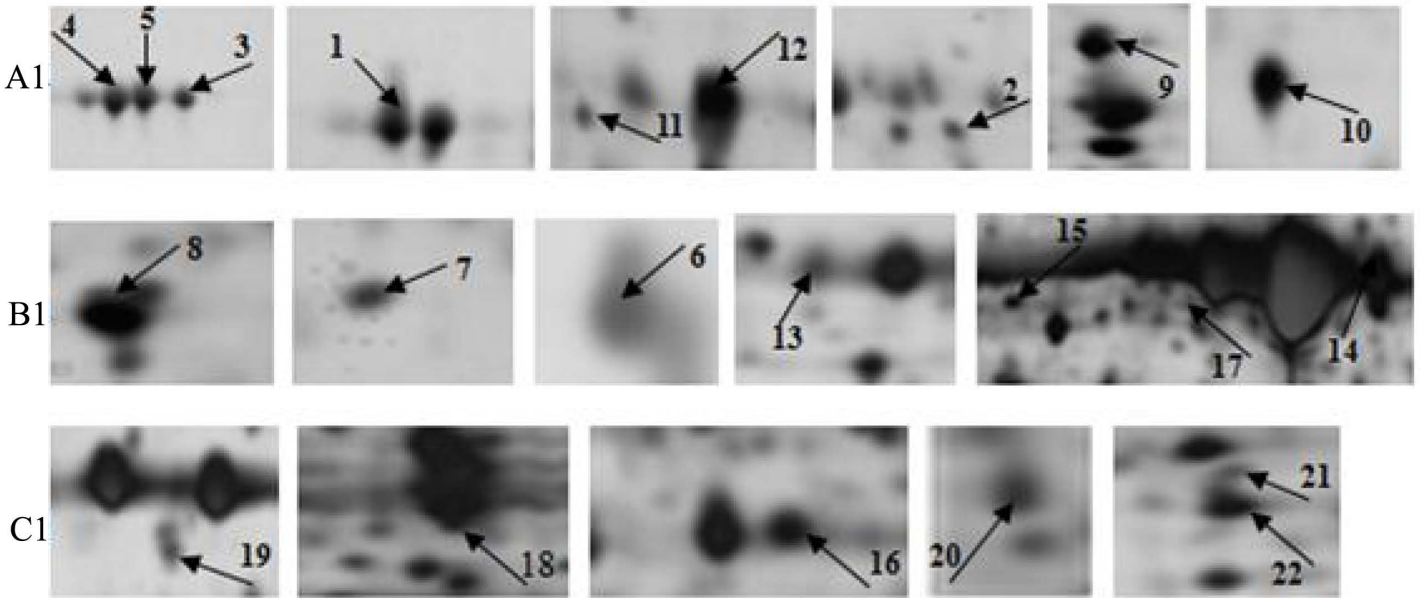

Figure 2. Enlargement of 22 differentially expressed protein spots on 2-DE gels from cotton leaf samples. (A), (B) and (C) were control group; (A1), (B1) and (C1) were salt-stressed group. Number 1 to 22 were 22 protein spots from Figure 1.

\subsection{MS Analysis of the Differentially Expressed Proteins of Cotton Leaves under Salt Stress}

Protein spots at the same position among different gels are considered to be the same proteins. A total of 22 protein spots (vol\% > 2) were excised from the A2 and B2 gels (Figure 1) for MALDI/TOF-TOF/MS analysis. GPS (Applied Biosystems, USA), MASCOT (Matrix Science, London, UK) and NCBI (National Center of Biotechnology Information) were selected for database searching. Overall, 14 protein spots were successfully identified (Table 1), but 8 protein spots were not identified with high confidence because of the low match scores (less than 45).

Numbers 1, 12, 13, and 14 are ribulose-1, 5-bisphosphate carboxylase/oxygenase (RuBisco) large subunit binding protein $\alpha$ subunit, RuBisco large subunit binding protein $\beta$ subunit, RuBisco kinase $\alpha 2$, and RuBisco large subunit, respectively. RuBisco enzyme exits in chloroplasts widely and serves as a key enzyme in carbon assimilation in all photosynthetic organisms. It is also involved in coordinating the relationship of photosynthesis and photorespiration. So we infer that cotton itself may regulate the expression of some key enzyme to promote the photosynthesis, thus enhancing the salt-tolerance of cotton. Number 2 is a luminal binding protein and is mainly responsible for the assembly of multi-subunit protein complexes in the endoplasmic reticulum. Numbers 3 to 5 are heat shock proteins 70 (HSP70), which are highly conserved and have many biological functions, including molecular chaperoning, cellular protection, and anti-apoptosis, which is also engaged in immunomodulation and has a key role in virus infection as well as disease research. Number 6 is a pathogenesis-related (PR) 
Table 1. Identification of differentially expressed proteins in leaves of tolerant versus sensitive cotton seedlings treated with salt stress.

\begin{tabular}{cccccc}
\hline Code & $\begin{array}{c}\text { Accession } \\
\text { no. }\end{array}$ & $\begin{array}{c}\text { MASCOT } \\
\text { Score*) }\end{array}$ & Mr(D)/pI & $\begin{array}{c}\text { Sequence } \\
\text { coverage (\%) }\end{array}$ & Identity \\
\hline 1 & gi|13410 & 270 & $52347 / 4.77$ & 27 & RuBisco large subunit-binding protein subunit alpha \\
2 & gi|211906506 & 203 & $73338 / 5.13$ & 37 & Luminal binding protein \\
3 & gi|1143427 & 87 & $75366 / 5.15$ & 14 & Heat shock protein 70 \\
4 & gi|1143427 & 237 & $75366 / 5.15$ & 19 & Heat shock protein 70 \\
5 & gi|1143427 & 330 & $75366 / 5.15$ & 32 & Heat shock protein 70 \\
6 & gi|10505372 & 400 & $17144 / 5.21$ & 77 & PR protein class 10 \\
8 & gi|21553644 & 72 & $32706.4 / 5.89$ & 28 & Quinone oxidoreductase-like protein \\
9 & gi|307948774 & 681 & $43083 / 5.51$ & 76 & S-adenosylmethionine synthetase \\
10 & gi|158144895 & 487 & $47753 / 5.49$ & 63 & Enolase \\
12 & gi|2506277 & 202 & $62945 / 5.85$ & 31 & RuBisco large subunit-binding protein subunit beta \\
13 & gi|78100212 & 144 & $46944 / 4.84$ & 7 & Ribulose activase alpha2 \\
14 & gi|4038534 & 54 & $45943 / 6.33$ & 7 & Ribulose large subunit \\
19 & gi|11563 & 169 & $53307 / 6$ & 4 & Onnamed protein product \\
22 & gi|302595736 & 133 & $28231 / 8.67$ & 7 & Oxygen-evolving enhancer protein 2 \\
\hline
\end{tabular}

protein class 10, which is localized in the cell wall and cytoplasm, interacts with its substrate nucleic acid, and has nuclease activity. Number 8 is a quinoneoxidoreductase-like protein, which catalyzes the respiration process and is a type of redox enzyme. Number 9 is an S-adenosylmethioninesynthetase, which catalyzes the biosynthesis of the methyl donor and precursor S-adenosylmethionine. Number 10 is an enolase. It plays an important role in the glycolysis pathway, catalyzing phosphoglycerate dehydration to form enolphosphopyruvate (PEP). Number 19 is an unnamed protein subunit. Number 22 is an oxygen-evolving enhancer protein 2, which is one of the three peripheral proteins in the plant photosynthetic system II (PSII).

\section{Discussion}

The complex and changeable nature of the proteome is closely related to the role played by proteins in cellular functions. In a living cell, apart from the housekeeping genes, most proteins are engaged in functional execution and response to environmental stimuli. Theoretically, when a living environment or cell function is altered, the proteome of the cell accordingly changes to adapt to varied environments [17]. In the current study, 14 differentially expressed proteins were successfully identified. The abovementioned proteins involved in photorespiration, cell defense, and amino acid metabolism are briefly discussed as follows:

1) Proteins involved in photorespiration: Numbers 1 and 12 in Zhong s9612 were the RuBisco large subunit binding proteins $\alpha$ and $\beta$ subunits, which play pivotal roles in photosynthesis. RuBisco is the key enzyme involved in photosynthetic carbon assimilation and modulates the relationship between photosynthesis and photorespiration. It also catalyzes $\mathrm{CO}_{2}$ fixation, the first step in photosynthesis, which promotes the combination of $\mathrm{CO}_{2}$ and ribulosediphosphate (RuBP) to form two copies of 3-phosphoglycerate. The first step in photorespiration, which is the combination of $\mathrm{O}_{2}$ and RuBP to form one copy of phosphoglyceric acid and one copy of phosphoric acid, is also catalyzed by RuBisco. Therefore, both photosynthesis and photorespiration are regulated by RuBisco, making it a critical enzyme in net photosynthesis [18] [19]. According to a previous study, salt stress can reduce RuBisco carboxylation efficiency in sapodilla, leading to reduced partial pressures in chloroplasts. This finding indicates that RuBisco can be limited by salt stress [20]. Number 8 is a quinoneoxidoreductase, a key component in electron transport chain that catalyzes the redox reaction in the respiration process. It can be divided into two categories, namely, the flavin- and zinc-binding quinoneoxidoreductases. 
Number 10 is an enolase, an important enzyme in the glycolysis pathway involved in dehydration reactions. When subjected to adversities such as oxygen deficiency, high salt concentrations, drought, and high and low temperatures, enolase gene expression and enzyme activity are correspondingly altered. Consequently, sufficient energy is supplemented for the recovery of photosynthetic injury caused by the excessive free radicals under stress conditions [21]. In the present study, RuBisco large subunit binding protein $\alpha$ subunit (Number 1), RuBisco large subunit binding protein $\beta$ subunit (Number 12), quinoneoxidoreductase (Number 8), and enolase (Number 10) were all upregulated after $24 \mathrm{~h}$ of salt stress, indicating that Zhong s9612 can promote photorespiration and maintain a fairly high degree of homeostasis to attenuate the salt stress injury by altering the expression of some critical enzymes. On the other hand, in Zhong 07, RuBisco large subunit (Number 14) was upregulated and RuBisco kinase $\alpha 2$ (Number 13) was downregulated, indicating that Zhong 07 is not sensitive to salt stress. The expression levels of some enzymes were elevated, rendering imbalance between living cells, which may be due to the different salt tolerance capacities of the salt-tolerant and salt-sensitive varieties. Thus, some enzymes have to be downregulated to maintain balance.

The OEE2 protein is one of the three peripheral proteins in PSII. Some studies have shown that OEE2 is involved in the association between $\mathrm{Ca}^{2+}$ and $\mathrm{Cl}^{-}$[22], which can stabilize PSII and maintain its biological function [23]. The main function of PSII is photosynthetic oxygen evolution, i.e., catalyzing water decomposition to release oxygen. Thus, the OEE2 protein exercises a positive effect on PSII stability and photosynthesis. After salt stress, the expression level of Number 32 was greatly upregulated, demonstrating that the salt-tolerant variety Zhong 07 can well coordinate the association of $\mathrm{Ca}^{2+}$ and $\mathrm{Cl}^{-}$and maintain PSII stability and function to withstand salt stress by enhancing OEE2 expression at an early stage.

2) Defense-related proteins: Number 2 is a luminal binding protein, which assembles multi-subunit protein complexes in the endoplasmic reticulum. Numbers 3 to 5 are all HSP70s, the most widely distributed and abundant protein in living cells. HSP70 is primarily engaged in de novo protein synthesis and transportation, as well as protein folding and degradation to maintain protein stability, improve cell tolerance to stimuli, strengthen the anti-oxidization effect, and sustain the basic function of living cells [24]. Number 6 is a PR10, which defends against external environmental stress. Park [25] believed that the high expression of PR10 in pepper root is most likely due to the induction of a partial constitutive defense mechanism in response to external environmental stress. After salt stress, Numbers 2 to 6 were all upregulated. This finding demonstrates that, at the initial stage of salt stress, Zhong s9612 could tolerate salt stress by the elevation of the auto-regulation ability to stress resistance.

3) Amino acid biosynthesis-related proteins: Number 9 is an S-adenosylmethioninesynthetase that catalyzes methionine to form S-adenosylmethionine. S-adenosylmethionine participates in phytohormone biosynthesis, such as polyamines and ethylene. The gene has been cloned in cotton, and its expression pattern in the roots Zhong s9612 has been analyzed. After $24 \mathrm{~h}$ of salt treatment, S-adenosylmethioninesynthetase was significantly downregulated. This result indicates that, at the early stage of salt stress, relevant metabolisms were slightly attenuated in Zhong s9612, implying reduced salt tolerance ability.

According to the comparative proteomic study of salt-stressed cotton leaves, salt stress can affect the leaf proteome of cottons with different salt tolerance abilities to various degrees. In this study we identified some salt-induced proteins, which had a big significance for the identification of salt tolerance of cotton varieties. From the results we discovered the expression of some proteins had changed a lot before and after the treatment, such as the RuBisco large subunit binding proteins $\alpha$ and $\beta$ subunits, OEE2 protein, HSP70, and S-adenosylmethioninesynthetase, so we infer that these proteins could be used as protein markers of salt tolerance identification in cotton.

\section{Acknowledgements}

The work was funded through the National High-Tech R\&D Program of China (2013AA102601). Yupeng Cui, Xuke Lu and Wuwei Ye participated in the design of the study, and performed major experiments, the data interpretation and drafted the manuscript. Weili Fan, Delong Wang and Junjuan Wang participated in part of the experiments. Shuai Wang and Zujun Yin performed part of proteomics analysis.

\section{References}

[1] Parida, A.K. and Das, A.B. (2005) Salt Tolerance and Salinity Effects on Plants: A Review. Ecotoxicology and Envi- 
ronment Safety, 60, 324-349.http://www.ncbi.nlm.nih.gov/pubmed/15590011

[2] Ward, J.M., Hirschi, K.D. and Sze, H. (2003) Plants Pass the Salt. Trends Plant Science, 8, 200-201. http://www.ncbi.nlm.nih.gov/pubmed/12758034

[3] Zhu, J.K. (2002) Salt and Drought Stress Signal Transduction in Plants. Annual Review Plant Biology, 53, 247-273. http://www.ncbi.nlm.nih.gov/pubmed/12221975 http://dx.doi.org/10.1146/annurev.arplant.53.091401.143329

[4] Ghosh, D., Tripathi, Y.K., Mujamdar, M.K., Kumar, R.V. and Prakash, V. (2006) Evaluation of Salt Tolerance Capability of Cotton (Gossypium hirsutum L.) Germplasm. Tropical Agriculture, 83, 30-36.

[5] Meloni, D.A., Oliva, M.A., Martinez, C.A. and Cambraia, J. (2003) Photosynthesis and Activity of Superoxide Dismutase, Peroxidase and Glutathione Reductase in Cotton under Salt Stress. Environmental and Experimental Botany, 49, 69-76. http://dx.doi.org/10.1016/S0098-8472(02)00058-8

[6] Li, X.X., Liu, B.X., Guo, Z.T., Chang, Y.X., He, L., et al. (2013) Effects of NaCl Stress on Photosynthesis Characteristics and Fast Chlorophyll Fluorescence Induction Dynamics of Pistaciachinensis Leaves. Ying Yong Sheng Tai Xue Bao, 24, 2479-2484. http://www.ncbi.nlm.nih.gov/pubmed/24417104

[7] Ashraf, M. (2002) Salt Tolerance of Cotton: Some New Advances. Critical Reviews in Plant Sciences, 21, 1-30. http://www.ingentaconnect.com/content/tandf/bpts/2002/00000021/00000001/art00001 http://dx.doi.org/10.1016/S0735-2689(02)80036-3

[8] Tripathi, A.K. and Tripathi, S. (1999) Changes in Same Physiological and Biochemical Characters in Albizialebbek as Bio-Indicators of Heavy Metal Toxicity. Journal of Environmental Biology, 20, 93-98.

[9] Sun, C.H., Du, W., Cheng, X.L., Xu, X.N., Zhang, Y.H., et al. (2010) The Effects of Drought Stress on the Activity of Acid Phosphatase and Its Protective Enzymes in Pigweed Leaves. African Journal of Biotechnology, 9, 825-833.

[10] Furtado, R.F., Mano, A.R.D., Alves, C.R., de Freitas, S.M. and Filho, S.M. (2007) Effect of Salinity on the Germination of Cotton Seeds. Revista Ciencia Agronomica, 38, 224-227.

[11] Meneses, C.H.S.G., Bruno, R.D.A., Fernandes, P.D., Pereira, W.E., de Morais Lima, L.H.G., de Andrade Lima, M.M. and Vidal, M.S. (2011) Germination of Cotton Cultivar Seeds under Water Stress Induced by Polyethyleneglycol-6000. Scientia Agricola, 68, 131-138. http://www.scielo.br/scielo.php?script=sci_arttext\&pid=S0103-90162011000200001\&lng=en\&nrm=iso\&tlng=en http://dx.doi.org/10.1590/S0103-90162011000200001

[12] Smith, L.H., Keys, A.J. and Michael, C.W.E. (1995) Striga hermonthica Decreases Photosynthesis in Zea mays through Effects on Leaf Cell Structure. Journal of Experimental Botany, 46, 759-765. http://dx.doi.org/10.1093/jxb/46.7.759

[13] Yu, L.N. and Pei, J. (2011) Application of Differential Proteomics in Mechanism Research of Acupuncture. Zhong Xi Yi Jie He Хue Bao, 9, 819-823. http://www.ncbi.nlm.nih.gov/pubmed/21849141

[14] Zhang, G.W., Lu, H.L., Zhang, L., Chen, B.L. and Zhou, Z.G. (2011) Salt Tolerance Evaluation of Cotton (Gossypium hirsutum) at Its Germinating and Seedling Stages and Selection of Related Indices. Ying Yong Sheng Tai Xue Bao, 22, 2045-2053. http://www.ncbi.nlm.nih.gov/pubmed/22097366

[15] Mechin, V., Damerval, C. and Zivy, M. (2007) Total Protein Extraction with TCA-Acetone. Methods in Molecular Biology, 355, 1-8. http://www.ncbi.nlm.nih.gov/pubmed/17093296

[16] Wu, X., Gong, F. and Wang, W. (2014) Protein Extraction from Plant Tissues for 2DE and Its Application in Proteomic Analysis. Proteomics, 14, 645-658. http://www.ncbi.nlm.nih.gov/pubmed/24395710 http://dx.doi.org/10.1002/pmic.201300239

[17] Kottapalli, K.R., Payton, P., Rakwal, R., Agrawal, G.K., Shibato, J., Burow, M. and Puppala, N. (2008) Proteomics Analysis of Mature Seed of Four Peanut Cultivars Using Two-Dimensional Gel Electrophoresis Reveals Distinct Differential Expression of Storage, Anti-Nutritional, and Allergenic Proteins. Plant Science, 175, 321-329. http://dx.doi.org/10.1016/j.plantsci.2008.05.005

[18] Law, R.D., Crafts-Brandner, S.J. and Salvucci, M.E. (2001) Heat Stress Induces the Synthesis of a New Form of Ribulose-1, 5-bisphosphate Carboxylase/Oxygenase Activase in Cotton Leaves. Planta, 214, 117-125. http://www.ncbi.nlm.nih.gov/pubmed/11762161 http://dx.doi.org/10.1007/s004250100592

[19] Spreitzer, R.J. (2003) Role of the Small Subunit in Ribulose-1,5-bisphosphate Carboxylase/Oxygenase. Archives of Biochemistry and Biophysics, 414, 141-149. http://www.ncbi.nlm.nih.gov/pubmed/12781765 http://dx.doi.org/10.1016/S0003-9861(03)00171-1

[20] Chaves, M.M., Flexas, J. and Pinheiro, C. (2009) Photosynthesis under Drought and Salt Stress: Regulation Mechanisms from Whole Plant to Cell. Annals of Botany, 103, 551-560. http://www.ncbi.nlm.nih.gov/pubmed/18662937 http://dx.doi.org/10.1093/aob/mcn125 
[21] Van der Straeten, D., Rodrigues-Pousada, R.A., Goodman, H.M. and Van Montagu, M. (1991) Plant Enolase: Gene Structure, Expression, and Evolution. Plant Cell, 3, 719-735. http://www.ncbi.nlm.nih.gov/pubmed/1841726 http://dx.doi.org/10.1105/tpc.3.7.719

[22] Hua, S.B., Dube, S.K., Barnett, N.M. and Kung, S.D. (1991) Nucleotide Sequence of Gene oee2-A and Its cDNA Encoding $23 \mathrm{kDa}$ Polypeptide of the Oxygen-Evolving Complex of Photosystem II in Tobacco. Plant Molecular Biology, 17, 551-553. http://www.ncbi.nlm.nih.gov/pubmed/1884009 http://dx.doi.org/10.1007/BF00040655

[23] Hua, S.B., Dube, S.K. and Kung, S.D. (1995) Organ-Specific Expression of the Nuclear Gene Encoding OEE2 of Photosystem-II Oxygen-Evolving Complex in Nicotiana tabacum. Journal of Plant Biochemistry and Biotechnology, 4, 109-111. http://dx.doi.org/10.1007/BF03262964

[24] Hurley, J.H. (1996) The Sugar Kinase Heat Shock Protein 70 Actin Super Family: Implications of Conserved Structure for Mechanism. Annual Review of Biophysics and Biomolecular Structure, 25, 137-162. http://www.ncbi.nlm.nih.gov/pubmed/8800467

[25] Park, C.J., Kim, K.J., Shin, R., Park, J.M., Shin, Y.C. and Paek, K.H. (2004) Pathogenesis-Related Protein 10 Isolated from Hot Pepper Functions as a Ribonuclease in an Antiviral Pathway. Plant Journal, 37, 186-198.

http://www.ncbi.nlm.nih.gov/pubmed/14690503

http://dx.doi.org/10.1046/j.1365-313X.2003.01951.x 
Scientific Research Publishing (SCIRP) is one of the largest Open Access journal publishers. It is currently publishing more than 200 open access, online, peer-reviewed journals covering a wide range of academic disciplines. SCIRP serves the worldwide academic communities and contributes to the progress and application of science with its publication.

Other selected journals from SCIRP are listed as below. Submit your manuscript to us via either submit@scirp.org or Online Submission Portal.
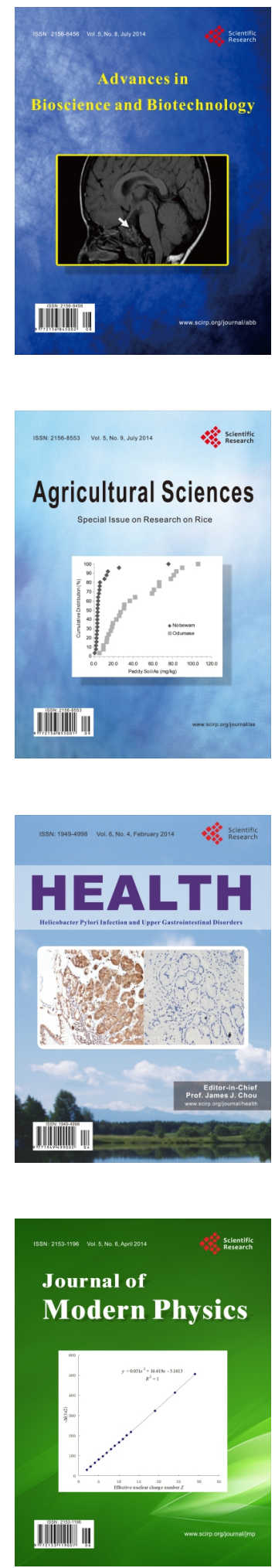
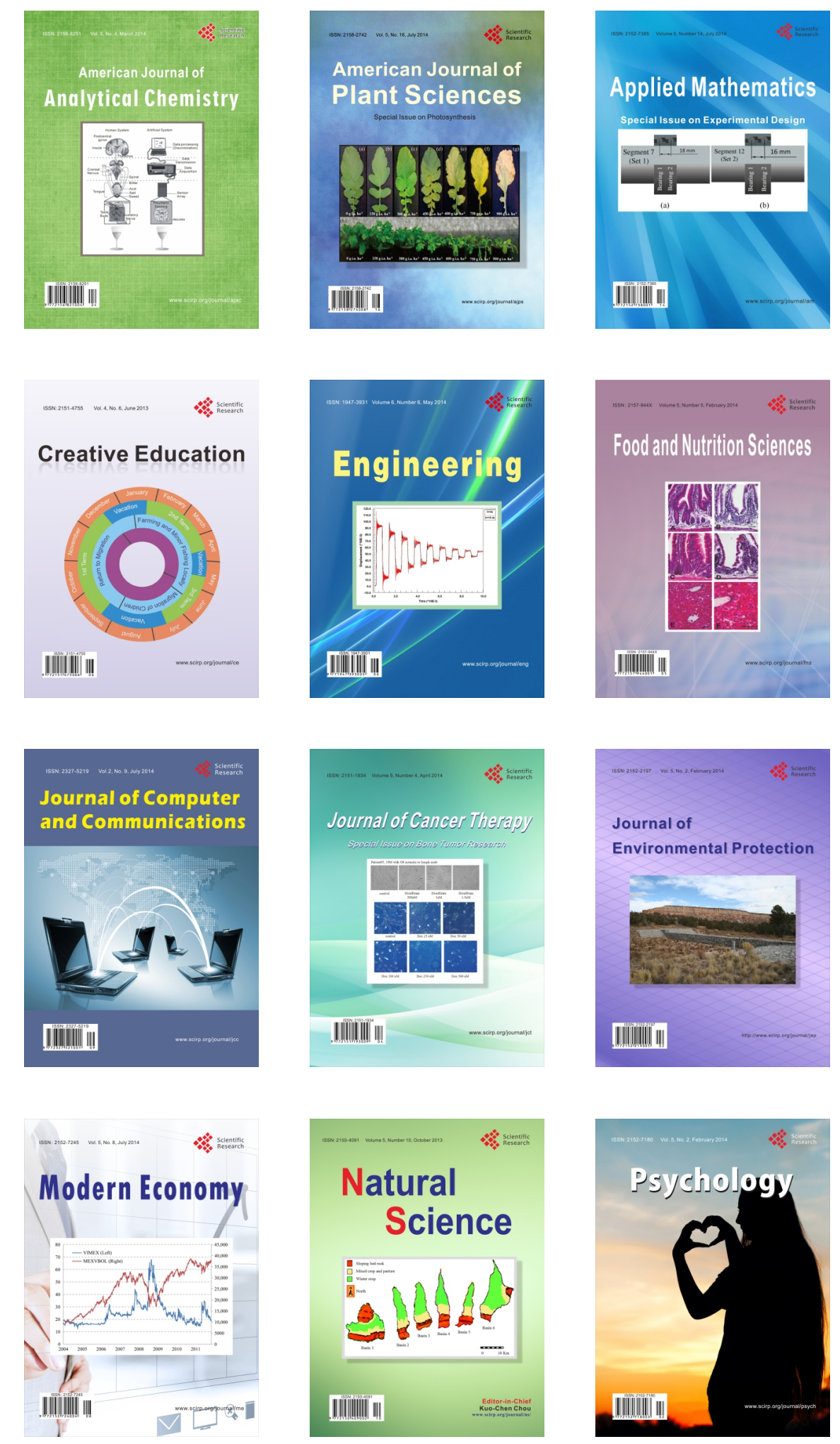